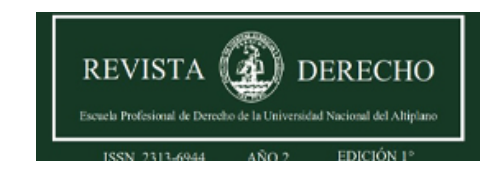

Revista de Derecho

ISSN: 2313-6944

ISSN: 2707-9651

revistaderecho@unap.edu.pe

Universidad Nacional del Altiplano

Perú

\title{
LA POSIBILIDAD JURÍDICA DEL MATRIMONIO HOMOAFECTIVO EN PERÚ
}

Calatayud Galindo, Guido

LA POSIBILIDAD JURÍDICA DEL MATRIMONIO HOMOAFECTIVO EN PERÚ

Revista de Derecho, vol. 5, núm. 1, 2020

Universidad Nacional del Altiplano, Perú

Disponible en: https://www.redalyc.org/articulo.oa?id=671870936006

DOl: https://doi.org/10.47712/rd.2020.v5i1.71

\section{(c) (1)}

Esta obra está bajo una Licencia Creative Commons Atribución 4.0 Internacional. 
Artículos de doctrina, análisis y crítica jurisprudencial

\section{LA POSIBILIDAD JURÍDICA DEL MATRIMONIO HOMOAFECTIVO EN PERÚ}

\section{THE LEGAL POSSIBILITY OF HOMOFECTIVE MARRIAGE IN PERU}

Guido Calatayud Galindo*

Universidad Nacional del Altiplano, Perú

gcalatayudg@est.unap.edu.pe
DOI: https://doi.org/10.47712/rd.2020.v5i1.71

Redalyc: https://www.redalyc.org/articulo.oa? $\mathrm{id}=671870936006$

Recepción: 01 Julio 2020

Aprobación: 04 Agosto 2020

Publicación: 10 Agosto 2020

\section{Resumen:}

El presente artículo analiza el matrimonio homoafectivo, en búsqueda de fundamentos dentro del ordenamiento jurídico peruano, a fin de establecer su posibilidad jurídica, conforme a los derechos humanos concretamente del derecho a la igualdad e identidad, a la idea del matrimonio. Asimismo plantea una alternativa para su reconocimiento.

Palabras Clave: Matrimonio, igualdad, género, identidad, discriminación.

\section{ABSTRACT:}

This article analyzes homo-affective marriage, in search of foundations within the Peruvian legal system, in order to establish its legal possibility, in accordance with human rights, specifically the right to equality and identity, to the idea of marriage. It also proposes an alternative for its recognition.

KEYWORDS: Marriage, equality, gender, identity, discrimination.

\section{INTRODUCCIÓN}

No se nace mujer, se llega a serlo.

Simone de Beauvoir.

Hoy alrededor de todo el mundo, existen familias que comparten experiencias de vida felices, tristes, emotivas, entre otras, familias que por tradición fueron protegidas y reguladas en la medida de lo posible por el derecho, pues el derecho no puede regular cuestiones de la subjetividad humana, sin embargo, también, por tradición, ha existido y existen familia, que concurren con las mismas experiencias de vida antes mencionadas, pero viven una experiencia de vida adicional, el rechazo y la discriminación.

El presente artículo, tiene como único fin aportar al debate nacional, elementos que permitan repensar las ideas, respecto de las familias conformadas por parejas del mismo sexo, familias que necesitan de un reconocimiento legal de sus relaciones.

Entonces partimos de la siguiente formulación, el reconocimiento, aceptación del matrimonio homoafectivo tiene alguna posibilidad real de vigencia y aplicación en el Perú ¿̇tiene el reconocimiento del matrimonio homoafectivo en el Perú algún sustento jurídico? Y de ser positiva la respuesta ¿Cuál es el camino a seguir?

\section{NotAs DE AUTOR}

* Estudiante de la E.P. Derecho de la Universidad Nacional del Altiplano 


\section{EL ORDENAMIENTO JURÍDICO PERUANO Y EL MATRIMONIO HOMOAFECTIVO}

\section{EL ORDENAMIENTO JURÍDICO Y EL ORDENAMIENTO LEGAL}

En el Perú Vidal Ramírez analiza concretamente la posibilidad jurídica, en su extenso estudio sobre el acto jurídico, respecto a sus requisitos de validez señalado "la posibilidad jurídica está referida a la conformidad con el ordenamiento jurídico de los derechos y deberes u obligaciones integrados en la relación jurídica generada por el acto jurídico" (2007, pág. 122).

Señala, el mencionado autor que la posibilidad jurídica no debe confundida con la licitud, pues esta última solo se vincula al ordenamiento legal, mientras que la posibilidad jurídica está vinculada a un ordenamiento jurídico, categoría más amplia (2007, pág. 122).

Entonces podemos colegir la siguiente idea, que lo legal tiene un contenido limitado en relación a lo jurídico, que tiene un contenido mucho más amplio pero ¿Cuál es el contenido de lo legal y lo jurídico?

Para responder a dicha pregunta citaremos a Guillermo Cabanellas quien define el término legal "Lo mandado por la ley. Lo contenido en ella. Conforme a su letra o a su espíritu. Legítimo; lícito” (1993, pág. 182). Y respecto a la definición de legalidad Guillermo Cabanellas sostiene "Calidad de legal o proveniente de la ley. Legitimidad. Licitud. Régimen político fundamental de un Estado; especialmente el establecido por su Constitución" (1993).

Resulta entonces valido sostener que la idea de legalidad tiene un soporte o fuente en el contenido de la leyes, siendo así los termino licito o legal son sinónimos, pues ambos tiene el mismo marco de referencia la ley, reglamentos o incluso a la propia Constitución según las definiciones citadas.

Respecto a lo jurídico responde en realidad a un campo mucho más amplio, aquí se entra al mundo de las normas jurídicas, que no son en realidad únicamente preceptos, disposiciones normativas o mejor artículos de una ley.

Ello derivado de la definición más ampliamente conocida del derecho, que sostiene que el derecho es un conjunto de normas. Siendo así nosotros vinculamos la idea de derecho con la juridicidad.

Como es sabido existen una diversa cantidad de normas tales como: normas religiosas, normas morales, normas de cortesía, normas de conducta, normas sociales, etc. Sin embargo el adjetivo de "jurídico", creemos deriva del origen de estas normas, es decir, que las normas jurídicas tiene un origen en el derecho.

Es aquí donde podemos encontrar una estrecha vinculación entre fuentes del derecho y el ordenamiento jurídico. Para Rubio Correa las fuentes del derecho son cinco: la legislación (ordenamiento legal), la jurisprudencia, la costumbre, la doctrina y la declaración de voluntad (2009, pág. 113).

Este análisis previo entre lo jurídico y lo legal, sirve para analizar la posibilidad jurídica del matrimonio homoafectivo. Pues en concreto se analizara si desde la doctrina y la jurisprudencia existe una base jurídica para la aceptación del matrimonio homoafectivo, asimismo si existe algún método para su inclusión.

\section{GENERALIDADES}

He decidido utilizar el término "matrimonio homoafectivo", en atención a las ideas esbozadas por el investigador Varsi Rospigliosi quien señala, que el termino homoafectivo, es mejor y menos denigrante que el termino homosexual (2011a, pág. 73).

La homoafectividad existió desde siempre, en la antigua Grecia fue aceptada y respetada, en Roma tolerada, posteriormente comenzó a ser rechaza, incluso señalada como una enfermadad, para finalmente ser tomada como algo natural (Varsi Rospigliosi, 2011b, pág. 106).

Dentro de esta era de la posmodernidad, el fenómeno homoafectivo alcanza un importante protagonismo, debido a la aceptación social de grupos sociales más abiertos y flexibles, ello en contra del modelo de familia heteroafectivo, el cual es rígido y no acepta sometimientos, significando esto un gran desafío para la humanidad (Mizrahi, 2016, pág. 3). 
Por el apoyo al grupo LGTBI en el Perú, y los casos (problemas derivados de su falta de regulación) que con mayor frecuencia se están presentando respecto de este sector de la población, está claro que el Perú tiene que asumir una postura que se halle conforme con los cánones del Sistema de Derechos Humanos.

Y es en ese contexto que resalta la idea de Varsi Rospigliosi cuando señala que, la Ley no puede ni debe ser ajena a la realidad, debe proyectar sus normas a fin brindar una adecuada protección a la familia, sin descuidar o limitar los derechos de las personas que la conforman (2011a, pág. 56).

Porque como bien señala el mencionado autor, tener un sistema familiar cerrado, es atentatorio al principio de protección de la dignidad humana (Varsi Rospigliosi, 2011a, pág. 58).

\section{LA IDEA DE MATRIMONIO Y EL CÓDIGO CIVIL}

Para el presente artículo es necesario entender en modo correcto ¿qué es el matrimonio? Al respecto Adame Gorddard aclara que, si bien es un error común, ver al matrimonio únicamente como un convenio, cuando esta es una de las formas de constituirlo (2017, pág. 59).

El estudioso Adame Gorddard señala que para definir en un modo adecuado el matrimonio debemos partir de una idea clave, el matrimonio es una relación humana (Addame Goddard, 2017, pág. 7).

El fundamento de esta idea podemos encontrarla en lo señalado por Varsi Rospigliosi cuando explica que el ser humano es un ser gregario que no solo vive en una comunidades, sino también junto a otros individuos, en suma, el hombre es un ser conyugal (2011b, pág. 27).

Ubicamos el origen primario del matrimonio, además de lo anterior señalado, en la atracción sexual y la concupiscencia (Varsi Rospigliosi, 2011b, pág. 28).

Por ende, como bien lo señala Adame Gorddard, el matrimonio no es una invención del Derecho, sino una obra de la libre voluntad de los contrayentes que han deseado esa unión (Addame Goddard, 2017, pág. 75).

Independientemente del concepto de matrimonio que se tenga para ciencias como la sociología, la sexología, entre otras ramas del conocimiento humano, el matrimonio tiene un significado más trascendental, idea compartida por Varsi Rospigliosi cuando señala, que el matrimonio implica la unión de un destino, entregarse y amarse, dentro de una comunidad de vida plena, donde existen dos personas que fijan un destino común (2011b, pág. 34).

El matrimonio según el Código Civil es "la unión voluntariamente concertada entre un varón y una mujer legalmente aptos para ella y formalizada con sujeción a las disposiciones de este Código, a fin de hacer vida en común". Contenido que no escapa a una interpretación abierta, como es el caso de la Constitución.

\section{LA HOMOAFECTIVIDAD}

A fin de que la idea de matrimonio homoafectivo sea entendida en su real sentido es menester aclarar algunas ideas, por ello nos apoyaremos en una publicación de La Comisión Nacional de Derechos Humanos de México

Se explica en dicho documento que el género es entendido, como el conjunto de las ideas y comportamientos que socialmente se esperan de los hombres y mujeres, en atención a un tiempo y lugar (Cervantes Medina, 2018, pág. 3).

El género implica un contexto social, histórico y simbólico basada en diferencias sexuales, entonces el género es un mandato del ordenamiento social (Barrios Alvarado \& Palomino Valencia, 2018, pág. 13).

Para Izquierdo, citado por Barrios Alvarado y Palomino Valencia, todo el medio o contexto espaciotemporal en el que los hombres y mujeres se relacionan e interactúan, funciona en base a relaciones de poder (2018, pág. 15).

Continua el citado autor señalando que el sexo se refiere, con mayor precisión, a las características biológicas (genéticas, hormonales, anatómicas y fisiológicas) a partir del cual las personas son clasificadas como mujeres o varones al nacer (Cervantes Medina, 2018, pág. 4).

Barrios Alvarado y Palomino Valencia, el sexo se sustentan en las diferencias biológicas, fisiológicas que constituyen tanto a una mujer como a un varón, de otro lado el género es una construcción histórica, psicosocial y cultural, con roles y papeles aprendidos por hombres y mujeres (2018, pág. 15). 
De ahí podemos colegir la principal diferencia entre sexo y género, el sexo es un dato o información física, incluso quizá cromosómica, mientras que el género es una construcción paulatina que se da en el transcurso de la vida humana, es decir, forma parte de la cultura sea propia o de una sociedad determinada.

De otro lado y especialmente importante para el tema del presente artículo, es precisar que significa la orientación o preferencia sexual, a la capacidad de cada persona de sentir una profunda atracción emocional, afectiva y sexual hacia otra persona, además de la capacidad de mantener relaciones íntimas y sexuales (Cervantes Medina, 2018, pág. 11).

La homosexualidad es entonces entendida como, la capacidad de una persona de sentir una profunda atracción emocional, afectiva, sexual y la capacidad de mantener relaciones íntimas y sexuales hacia personas de su mismo género (Cervantes Medina, 2018, pág. 11). Ello bajo la idea no de proteger a un solo modelo o tipo de familia (nuclear heretoafectiva).

\section{LAS POSTURAS MODERNAS DEL DERECHO DE FAMILIA}

Consideramos importante que a fin de resolver nuestra duda inicial, no solo debemos recurrir a un enfoque constitucional como se hará, sino también a aquella rama especializada en la materia, es decir, el Derecho de Familia, o mejor aún, siguiendo la terminología planteada por Berenice Díaz, seguida en el Perú por Varsi Rospigliosi quien señala, que un término más adecuado para esta rama es la de Derecho de las Familias (Varsi Rospigliosi, 2011a, pág. 23).

Es en esta rama del Derecho donde muchos detractores de la postura asumida en el presente artículo señala que la familia tiene un fin eminentemente procreacional, idea que es parcialmente correcta, pues contrario sensu, no solo generan una limitación a las uniones homoafectivas, sino también a las propias uniones heteroafectivas, pero con cónyuges infértiles (Varsi Rospigliosi, 2011a, pág. 41).

Entonces bien señala Varsi Rospigliosi, que estas nuevas consideraciones hacen que la capacidad de procreación no es un requisito para la conformación de una familia, ni mucho menos es un fin absoluto como antes (2011a, pág. 41).

Ahora bien, consideramos que uno de los pilares fundamentales para la regulación tuitiva y protectora que debería tener el Estado respecto del matrimonio y la familia, radica en el siguiente elemento, la comunidad de vida.

La comunidad de vida para Varsi Rospigliosi, involucra el deseo de hacer vida en común, de compartir, para llegar a una integración familiar, que se fundamenta en las vivencias (2011b, pág. 48).

Consideramos que dicho elemento, siempre ha existido en las relaciones familiares y en el matrimonio, aunque con otras denominaciones de igual modo, y sin menos importante ha existido el poderoso elemento, modernamente denominado, como la socioafectividad.

Varsi Rospigliosi escribió hace algunos años, un artículo sobre la socioafectividad y las relaciones filiales, en dicho artículo enseña, que la socioafectividad es un elemento siempre presente en las relaciones familiares, que se funda en el deseo y voluntad de las personas que afirmar permanentemente sus vínculos afectivos, hecho que evidentemente trasciende al Derecho (Varsi Rospigliosi \& Chaves, 2010, pág. 59).

Posteriormente menciona el poder jurídico de dicho elemento mediante el siguiente razonamiento, en el pasado las relaciones paterno filiales se fundaban en criterios únicamente biológicos, pero en la actualidad dicho criterio se ubica a lado del criterio socioafectivo, ambos establecen la existencia de vínculos parentales (Varsi Rospigliosi \& Chaves, 2010, pág. 59).

Dicho vinculo parental evidencia para nosotros, una autentica relación jurídica, ello implica el verdadero valor de la socioafectividad, que cuando es tan fuerte como es el caso de las parejas estables, miembros de una familia, etc.

\section{QUE DICE LA JURISPRUDENCIA}

a) Primeras resoluciones del Perú

Dentro de mi investigación dentro del contexto peruano, me fue posible ubicar los siguientes casos relevantes, para los fines del presente artículo: 
- Óscar Ugarteche y Fidel Aroche contra la RENIEC.

- Susel Paredes y Gracia Aljovil contra la RENIEC.

- Andree Martinot con Diego Urbina contra la RENIEC.

Casos que no han pasado desapercibido por la sociedad peruana, ni menos por los medios de prensa serios.

"Poder Judicial reconoció matrimonio gay de Susel Paredes: El Primer Juzgado Constitucional de la Corte Superior de Lima declaro fundado el recurso de amparo de la pareja contra RENIEC para que reconozca el matrimonio", con esta portada se imprimieron las hojas del diario La República en fecha 05 de abril de 2019.

Ello implica que un diario serio, reconoció a esta como la noticia más importante en todo el Perú, el que un Juez reconoció el matrimonio gay dentro del Perú.

Toca el turno pues de analizar los tres casos antes mencionados a fin de conocer cuál es la postura jurídica que empieza a desarrollarse en el Perú.

a) Óscar Ugarteche y Fidel Aroche contra la RENIEC

Este caso se remonta al año 2012, año en el cual Óscar Ugarteche contrae matrimonio con Fidel Aroche, en la ciudad de México, para posteriormente solicitar su inscripción ante el RENIEC, pedido que también es denegado en las diferentes instancias administrativas, por lo cual acude al Poder Judicial mediante una demanda de amparo, la cual fue bien acogida bajo los siguientes fundamentos:

- Fundamento 10 y 11: El Juzgado hace recuerdo de la especial protección que merece: la dignidad humana, el libre desarrollo y la igualdad ante la Ley.

- Fundamento 12: Se realiza una aplicación extensiva de los principios de Yogyakarta, que es un documento internacional que orienta la interpretación y aplicación de los derechos humanos, especialmente de sujetos entre los cuales se hallan los homosexuales.

- Fundamento 17: También se hace una aplicación de la interpretación evolutiva, mediante el cual se establece que la Constitución es un árbol vivo y que mediante una interpretación evolutiva se acomoda a la realidad.

- Fundamento 21 al 23: El Juzgado señala, que es altamente discriminatorio que se niegue la inscripción del matrimonio en cuestión, por la falta de argumentos razonables y objetivos.

- Fundamento 32: La Observación General N² 20, del Consejo Económico y Social, que en cuanto a la discriminación por cualquier otra índole señala, que se incluye a la orientación sexual, no son un obstáculo para el ejercicio de sus derechos.

b) Susel Paredes y Gracia Aljovil contra la RENIEC

Los hechos se remontan al 04 de agosto de 2016, fecha en la cual Susel Paredes y Gracia Aljovin se casaron en la ciudad de Miami, matrimonio que fue perfectamente celebrado, luego de ello la pareja se traslada al Perú para vivir, siendo así es que presentaron su partida de matrimonio ante el RENIEC para solicitar el registro correspondiente.

Sin embargo, RENIEC negó su pedido en dos instancias administrativas, debido a que sostienen que solo son eficaces los matrimonios entre personas de diferente sexo, posteriormente la pareja presento una acción de amparo para que se declaren nulas las resoluciones administrativas de RENIEC, de modo resumido la decisión por parte del Juzgado fue, la inexistencia de restricciones constitucionales respecto de las parejas del mismo sexo, y que las disposiciones del Código Civil afecta los derechos fundamentales de la pareja.

La Sentencia del Décimo Primer Juzgado Constitucional, tiene entre sus principales argumentos los siguientes:

- Se parte de la premisa de un matrimonio homoafectivo celebrado en el extranjero, y si se presenta un caso de inaplicación de las normas civiles (control difuso o convencional).

- Fundamento 32: el orden cronológico, la Constitución al ser posterior al Código Civil, deja a esta norma o a una eventual futura norma, el desarrollo constitucional de la familia y el matrimonio.

- Fundamento 33: El concepto de familia, tiene un desarrollo evolutivo dentro del marco del Derecho. 
- Fundamento 36 y 38: Existe el denominado Control de Convencionalidad, mediante el cual se inaplica las normas del derecho interno, por las normas de la Convención Americana de Derechos Humanos. Dicho control lo pueden realizar los tribunales nacionales.

- Fundamento 44 y 45: El control convencional, no solo se realiza en atención a normas de convención, sino también en atención a las Opiniones Consultivas, aún en las que el Estado no haya sido parte. Ello en atención a la Opinión Consultiva $\mathrm{N}^{\circ} 21-2014$.

- Fundamento 47 y 50: La Opinión Consultiva $\mathrm{N}^{\circ}$ 24-2017, sobre identidad de género y no discriminación de parejas del mismo sexo, que básicamente reconoce que puede existir un vínculo familiar derivadas de las parejas del mismo sexo. Ello en respeto a la igualdad, sin poder existir discriminación en razón de sexo.

- Fundamento 57: La familia debe ser entendida en forma amplia y de acuerdo a la evolución social, se debe brindar protección a las familias compuestas por personas del mismo sexo.

c) Andree Martinot con Diego Urbina contra la RENIEC.

Andree Martinot celebra su matrimonio con Diego Urbina en la ciudad de Nueva York, en el 01 de abril del 2015, luego de ello la pareja decide residir en la ciudad de Lima, razón por la cual demanda a la RENIEC, a fin de que esta inscriba su matrimonio, pues la pareja tenía conocimiento de que similares solicitudes eran denegadas. Siendo así que el Poder Judicial emite una sentencia con los siguientes fundamentos:

- Se parte de la premisa, que se demanda la posibilidad de una inscripción de un matrimonio previamente celebrado, distinto a la posibilidad de celebración de esta clase de matrimonios en el Perú.

- Fundamento 6: El Tribunal Constitucional en su sentencia $\mathrm{N}^{\circ}$ 2868-2004-AA/TC, concretamente en su fundamento 14 , señalo que el derecho a contraer libremente el matrimonio, no tiene propiamente una autonomía constitucional, como la libertad contractual o de empresa, religión, pero, se encuentra dentro del ámbito de protección del derecho al libre desarrollo de la persona, componente de la dignidad humana.

En estos tres casos, los magistrados en muchas ocasiones hicieron uso de fundamentos similares, pero señalamos aquellos fundamentos que constituyen la razón de la sentencia, aunque sin repetir los ya mencionados.

Queremos señalar, que si bien, en los casos antes analizados, resuelven una duda ¿es posible la inscripción de un matrimonio homoafectivo celebrado en el extranjero, frente a la RENIEC?, pero, nos preguntamos si ¿estos fundamentos únicamente sirven para resolver la anterior duda, o van más allá, y a futuro pueden ser razones válidas para el reconocimiento de las uniones homoafectivas?, creemos que la respuesta a esta interrogante es positiva.

b) Jurisprudencia internacional

La Corte Interamericana de Derechos Humanos, tiene dentro sus atribuciones o facultades el de poder opinar, respecto de las diversas consultas que tengas los Estados americanos afiliados, para la correcta interpretación de la Convención y sus alcances.

Siendo así es que emite la Opinión Consultiva $\mathrm{N}^{\circ} 24-17$, sobre identidad de género e igualdad y no discriminación a parejas en relación con el cambio de nombre, la identidad de género y los vínculos entre parejas del mismo sexo.

En ella puntualmente señala los siguientes elementos importantes (Opinión Consultiva $\mathrm{N}^{\circ}$ 024-2017, 2017):

- Dentro de las consideraciones generales, señala lo antes mencionado sobre género, sexo, orientación sexual, pero añade algo novedoso, la heteronormatividad, entendida como la preferencia a favor de las relaciones heteroafectivas, entendidas como naturales, preferidas por encimas de las reacciones homoafectivas.

- Párrafo 61: La corte acertadamente señala, la noción de igualdad, se desprende de la naturaleza del género humano, inherente a las dignidad humana, siendo incompatible toda situación de superioridad.

- Párrafo 70: Se señala que las otras condiciones sociales, por la cuales no se puede discriminar a otra persona puede contener el elemento de la orientación sexual, en atención a la interpretación pro homine. 
- Párrafo 81: Enseña que para hacer un trato diferenciador se debe realizar un test de igualdad, que no es otro que el test de proporcionalidad, iniciando con él a) test de idoneidad: se parte de la identificación de un fin legítimo, y sobre la idoneidad de la medida; b) test de necesidad: parte de identificar si es la única medida posible, o existen otras, para luego verificar que el uso de otras medidas menos gravosas de los derechos; y c) test de proporcionalidad: que implica que el fin legitimo conseguido resulte más beneficioso en comparación a la medida impuesta.

$\mathrm{Al}$ respecto podemos agregar, dentro del marco jurídico nacional, la medida de limitación al matrimonio homoafectivo, no encuentra actualmente un fin constitucional y convencionalmente legítimo.

- Párrafos 174 al 176 y el 179: La Convención Americana no maneja un concepto cerrado de familia, en cuanto a su protección, ello debido a que la familia es una institución social. Determina que la familia puede estar conformada por personas de diversas identidades de género u orientaciones sexuales.

- Párrafo 189: En relación a lo antes mencionado refiere que, una interpretación restrictiva del concepto de familia, que excluya de la protección interamericana al vínculo afectivo entre personas del mismo sexo, frustraría el objeto y fin de la Convención.

- Párrafo 221: La Corte advierte que la tesis de la procreación como fin determinante de la familia, no es adecuada, dado que resulta degradante para las personas casadas o no, que carecen de la capacidad generandi $\mathrm{o}$ incluso de las que no tienen tal interés.

- Párrafo 190: Es más, la propia Corte señala que igual que su par Europeo, coinciden en señalar que la distinción entre relaciones homo y heteroafectivas, es una distinción artificial, que no atenta contra la idea de familia, por el contrario, reconoce la dignidad de las personas que conforman las relaciones homoafectivas.

- Párrafo 196: Señala que los Principios de Yogyakarta, son principios de aplicación al Derecho Internacional, que señala dentro de su contenido, que los Estados deben tomar las medidas adecuadas a fin de que se elimine cualquier forma de discriminación que tengan como fundamento la orientación sexual o la identidad de género.

- Párrafo 198: De otro lado la Corte también enseña que, el alcance de la protección al vínculo familiar derivado de las relaciones homoafectivas, trasciende el ámbito patrimonial, por el contrario se extiende sobre todos los derechos y obligaciones de los vínculos derivados de las relaciones heteroafectivas.

- Párrafo 224: Finalmente señala la Corte, crear una institución con efectos similares o iguales al matrimonio, pero con una denominación especial, carece de sentido, pues implica una diferencia artificial, es más, ello resulta discriminatorio.

Resulta claro, que los efectos de una Opinión Consultiva, no es comparable a los efectos de una sentencia en materia contenciosa, sin embargo, consideramos que sus efectos jurídicos son importantes y vinculante porque, fue emitida por la Corte Interamericana de Derechos Humanos el organismo especializado, que lejos de aplicar o limitar su contenido a un caso concreto, lo hace en forma general, es decir, el contenido de dicha opinión tendrá un alcance general en sus futuras decisiones.

\section{NORMAS INTERNACIONALES}

La cuarta disposición final y transitoria de la Constitución Política del Perú expresa que, las normas relativas a los derechos y las libertades que la Constitución reconoce se interpretan de conformidad con la Declaración Universal de los Derechos Humanos y con tratados y acuerdos internacionales sobre las mismas materias ratificadas por Perú.

Siendo así es importante mencionar que le Pacto de San José de Costa Rica o Convección Interamericana de Derecho Humanos tiene efectos pleno en el Perú, más aun cuando el artículo $55^{\circ}$ de la Constitución expresa que los tratados forman parte del ordenamiento interno.

La estudiosa Graciela Medina clasifica las normas internacionales según regulen el derecho a casarse y el derecho al matrimonio (Medina, págs. 197-208).

a) Derecho a casarse: 
- Declaración Universal de los Derechos Humanos de 1948, que en su artículo $16^{\circ}$ inciso $1^{\circ}$, señala que los hombres y las mujeres, a partir de la edad núbil, tienen derecho, sin restricción alguna por motivos de raza, nacionalidad o religión, a casarse y fundar una familia.

- Pacto se San José de Costa Rica de 1969 , que en su artículo $17^{\circ}$ inciso $2^{\circ}$ señala se reconoce el derecho del hombre y la mujer a contraer matrimonio y fundar una familia si tienen edad y las condiciones requeridas para ello por las Leyes internas, en la medida que estas no afecten el principio de no discriminación.

b) Derecho a fundar una familia:

a. Pactos Internacionales de Derechos Económicos, Sociales y Culturales de 1966, que en su artículo $10^{\circ}$ señala que se debe conceder a la familia, que es el elemento natural y fundamental de la sociedad, la más amplia protección y asistencia posibles.

b. Declaración Americana de los Derechos y Deberes del Hombre de 1948, en su artículo VI señala que, toda persona tiene derecho a constituir familia, elemento fundamental de la sociedad, y a recibir protección para ella.

\section{LA DIGNIDAD HUMANA Y PRINCIPIO DE IGUALDAD E IDENTIDAD}

La dignidad, no puede ser comparada con otros derechos o valores, como bien ha enseñado Lucía Castro, la dignidad es un valor absoluto, que es la base, fundamento y fin del sistema mismo de derechos humanos, del cual se derivan los demás derechos y valores (2017, pág. 8).

Dentro contenido esencial de la dignidad o su núcleo duro encontramos al derecho a la igualdad, se debe tener en cuenta que este derecho tiene dos dimensiones: a) Igualdad ante la Ley; b) Igualdad en la Ley (Castro Barnechea, 2017, pág. 9).

El Tribunal Constitucional en el Exp. $\mathrm{N}^{\circ}$ 02835-2010-PA/TC, señala que por la primera de ellas se entiende, a la aplicación de las normas a todos por igual, en tanto que la segunda, implica que un órgano no puede modificar arbitrariamente el sentido de sus decisiones en casos sustancialmente iguales, que es un límite al legislador (Castro Barnechea, 2017, págs. 9-10).

En similar aspecto enseña Eguiguren sobre la igualdad predicada desde una perspectiva constitucional, tanto como un principio, entendido como una directriz de un estado democrático de derecho; y de otro lado como un derecho constitucional subjetivo, individualmente exigible, que confiere a toda persona los siguientes derechos: a) derecho a ser tratado con igualdad ante la ley; y b) el derecho a no ser objeto de discriminación (15, pág. 63).

Fernández Sessarego citado por Delgado Menéndez explica que, junto a la identidad, la vida y la libertad constituyen la trilógica de los intereses o valores esenciales entre los esenciales (2016, pág. 17).

Delgado Menéndez encuentra el origen del derecho a la identidad personal en la jurisprudencia italiana, en donde sus jueces sostienen que tal derecho debe ser objeto de reconocimiento y tutela jurídica autónoma (2016, págs. 17-18).

A criterio de Delgado Menéndez la concepción contemporánea de la identidad se puede bifurcar en una identidad dinámica y una identidad estática (2016, pág. 15).

Debemos entender según Fernández Sessarego citado Delgado Menéndez por identidad estática, a la identificación, ya sea física, biológica, registral u otra, mientras que la identidad dinámica está vinculada a la verdad personal o proyecto de vida, ello implica la proyección social de la persona (2016, pág. 15).

La Corte Interamericana de Derechos Humanos en el caso María Elena Loayza Tamayo vs. Perú a sustentado la íntima relación entre el proyecto de vida y la realización personal, que implica las opciones que el sujeto pueda tener para dirigir su vida y alcanzar su metas.

El Estado no puede limitar las relaciones homoafectivas, por ende, mucho menos, como lo señala Varsi Rospigliosi, limitar su acceso a la familia, debido a que la exclusión de ciertos modelos familiares, afectan el principio de protección a la dignidad (2011a, pág. 46).

a) El enfoque o perspectiva de género 
El enfoque o perspectiva de género, tuvo una tarea inicial bien definida, que mediante esta, se llegue a una clara diferencia en la organización social, respecto de las diferencias de sexo, sin que ello implique situaciones de desigualdad (Miranda Novoa, 2012).

Ello mediante una argumentación relacional, pero, como dijimos, el enfoque o perspectiva de género estaba orientado únicamente a la diferencia entre géneros, creemos que su radio o objeto puede ser ampliado, a el campo de la orientación o preferencia sexual.

Para sostener esto, citamos las ideas de Ruiz Bravo, quien ubica precisamente dentro del enfoque de o perspectiva de género, a los sistemas de género, es decir, el cómo la sociedad determina define la sexualidad y la procreación, y con ello también a la orientación sexual, identidad sexual y derecho a la igualdad (Ruíz Bravo, 1999, pág. 47).

Para Castro Barnechea es viable considerar dentro que los grupos conformados que las diversas sexualidades, a los no heterosexuales, lesbianas, gays, tras, entre otros (Castro Barnechea, 2017, pág. 22).

En ese entender, el enfoque de género, es un instrumento con una importante finalidad, cual es impregnar de manera transversal, las leyes, instituciones y sistemas organizativos de la sociedad en el ideal de la igualdad (Miranda Novoa, 2012, pág. 347), como referimos antes, no solo entre varones y mujeres, sino también entre personas homosexuales y heterosexuales, y por nuestra parte, también a sus relaciones.

\section{EL MÉTODO DE RECONOCIMIENTO}

Para el caso peruano, consideramos que existen dos vías para el reconocimiento del reconocimiento de las relaciones homoafectivas, la vía legislativa y la vía de control jurisdiccional, resulta que los fundamentos antes señalados, pueden fundamentar el reconocimiento mediantes ambas vías.

Pero nos centraremos más en el control jurisdiccional, por el mediante el cual se puede llegar a un reconocimiento más rápido y en atención a los pronunciamientos pendientes del Tribunal Constitucional desde hace varios años.

Dentro de la doctrina del Derecho Constitucional y Derecho Procesal Constitucional, existe un principio rector es cual es denominado de supremacía constitucional, mediante el cual, no puede ni debe existir incompatibilidad entre la Constitución y las normas legales.

Ampliando esta idea, resulta que la moderna doctrina internacional, reconoce igual supremacía u obligatoriedad en las normas convencionales, como es el caso de la Convención Interamericana de Derecho Humanos, las cortes y tribunales, en atención a lo antes mencionado puede y de hecho están obligados, a ejercer un control convencional y/o constitucional. Bajo la idea de una mejor protección a los derechos de las personas y en beneficio del principio pro homine o pro persona.

El Control de Convencionalidad fue una creación de la propia Corte Interamericana de Derechos Humanos, en el caso Almonacid Arellano y otros contra el gobierno de Chile, señalando que si bien los jueces y tribunales internos están sujetos al imperio de la Ley y la Constitución, cuando un Estado ratifica un tratado internacional, sus jueces también están sometidos a dicho tratado, por ende, se les obliga a los fines de la Convención no sean reducidos por las Leyes contrarias (Eduardo Ferrer Mac-Gregor, 2012, pág. 4).

Ello permite evidenciar que nuestro país, independientemente del bloque de constitucionalidad existente en nuestro orden jurídico, tiene que ser compatible además con el bloque de Convencionalidad, y ello se aprecia aún más en atención al principio interpretativo pro homine (Eduardo Ferrer Mac-Gregor, 2012, pág. 17).

Asimismo, debemos tener en cuenta que la propia Corte Interamericana de Derechos Humanos, ya ha señalado que se tiene como objeto del Control de Convencionalidad, no solo en base a los pronunciamientos de la Corte en materia contenciosa, sino también a sus pronunciamientos en materia no contenciosa o consultiva, ello según la Opinión Consultiva N²1-14.

El Control Convencional guarda una especial semejanza con el Control Constitucional, incluso en la forma de su ejercicio, que puede ser concentrado o difuso, es decir, en nuestro país el Tribunal 
Constitucional, puede dejar sin efecto y por ende expulsar del ordenamiento nacional, Leyes e incluso preceptos Constitucionales (Eduardo Ferrer Mac-Gregor, 2012, pág. 12).

\section{CONCLUSIONES}

Luego de elaborado el presente artículo podemos arribar las siguientes conclusiones:

a) Existe válidamente argumentos jurídicos que permiten el reconocimiento del matrimonio homoafectivo en Perú (posibilidad jurídica).

b) El matrimonio, tiene sus origines en las relaciones humanas, particularmente entre relaciones humanas derivadas del amor entre personas del género humano.

c) La idea de homoafectividad, es decir, una relaciones entre personas del mismo sexo o género, es una realidad y su existencia deriva igualmente de las relaciones amorosas

d) El matrimonio y sus fines, en estricto, no son limitantes del reconocimiento de las relaciones homoafectivas, desde una interpretación pro homine.

e) Existe jurisprudencia en el Perú, que ya ha comenzado a señalar una gran cantidad de fundamentos jurídicos (doctrina y jurisprudencia), que permiten reconocer explícitamente que los matrimonios homoafectivos pueden ser válidamente reconocidos en el Perú

f) La existencia de un método de interpretación pro homine y de control convencional, que permitiría resolver el tema de las uniones homoafectivas, mediante la Opinión Consultiva $\mathrm{N}^{\circ}$ 24-17.

g) Los derechos a la identidad y la igualdad, será limitados siempre que el acceso al matrimonio como tal este restringido a las uniones homoafectivas.

\section{BIBLIOGRAFÍA}

Addame Goddard, J. (2017). ¿Quées el matrimonio? Su naturaleza ética y jurídica. México: Instituto de Investigaciones Jurídicas UNAM.

Barrios Alvarado, E., \& Palomino Valencia, M. A. (2018).Pensando en Género: Marco conceptualpara la administración de justicia con enfoque de género. Lima: Fondo Editorial del Poder Judicial.

Cabanellas de Torres, G. (1993). Diccionario Jurídico Elemental. Argentina: Heliastra.

Castro Barnechea, C. L. (2017). El Matrimonio Igualitario: Marcando un hito en la lucha contra la discriminación. El Derecho a la igualdad y no discriminación por orientación sexual aplicado al acceso al matrimonio en el Perú (Tesis de Maestria). Pontificia Universidad Católica del Perú, Lima.

Cervantes Medina, J. C. (2018). Los Derechos Humanos de las Personas Transgénero, Transexual y Trasvestis. México: Comisión Nacional de los Derechos Humanos.

Delgado Menéndez, M. d. (2016). El derecho a la identidad: una visión dinámica . (Tesispara optar el grado de Magister en investigación jurídica). Pontificia Universidad Católica del Perú Escuela de Posgrado, Lima.

Eduardo Ferrer Mac-Gregor. (2012). Control de Convencionalidad Ejercido por los Tribunales y Salas Constitucionales. En E. Coord. Ferrer Mac-Gregor, Control Difuso de la Convencionalidad. México: Fundap. Recuperado el 20 de octubre de 2019, de http://www.ernestojinesta.com/_REVISTAS/CONTROL\%20DE\%20CONVENCIONALIDAD\%20EJ ERCIDO\%20POR\%20LOS\%20TRIBUNALES\%20Y\%20SALAS\%20CONSTITUCIONALES.PDF

Eguiguren Praeli, F. J. (15). Principio de igualdad y derecho a la no discriminación. Ius et veritas, 63-72.

Medina, G. (s.f.). Los homosexuales y el derecho a contraer matrimonio. Buenos Aires: Rubinzal- Culzoni.

Miranda Novoa, M. (2012). Diferencia entre la Perspectiva de Género y la Ideología de Género. Dikaión(21), 337-356.

Mizrahi, M. L. (2016). Homosexualidady Transexualismo. Bogotá: Astrea - Universidad del Rosario. 
Opinión Consultiva N 024-2017 (Corte Interamericana de Derechos Humanos 24 de noviembre de 2017). Recuperado el 20 de octubre de 2019, de http://www.corteidh.or.cr/docs/opiniones/seriea_24_esp.pdf

Rubio Correa, M. (2009). El Sistema Jurídico introducción al derecho. Lima: Fondo Editorial de la Pontificia Universidad Católica del Perú.

Ruíz Bravo, P. (1999). Sobre género, Derecho y discriminación. Lima: Pontificia Universidad Católica del Perú; Defensoria del Pueblo.

Varsi Rospigliosi, E. (2011a). Tratado de Derecho de Familia Tomo I. Lima: Gaceta Jurídica.

Varsi Rospigliosi, E. (2011b). Tratado de Derecho de Familia Tomo II. Lima: Gaceta Jurídica.

Varsi Rospigliosi, E., \& Chaves, M. (2010). Paternidad Socioafectiva la evolución de las relaciones paterno- filiales del imperio del biologismo a la consagración del afecto. Actualidad Jurídica(200), 57-64.

Vidal Ramirez, F. (2007). El acto jurídico. Lima: Gaceta Jurídica. 